\title{
Contributions of Educational Psychology to University Education
}

\author{
Luz Marina Méndez Hinojosa \\ Psychological Research Center, Department of Psychology, Autonomous University of Nuevo Leon, \\ Monterrey, Mexico \\ Email: lucymendezhinojosa@hotmail.com
}

Received 24 January 2015; accepted 9 February 2015; published 12 February 2015

Copyright (C) 2015 by author and Scientific Research Publishing Inc. This work is licensed under the Creative Commons Attribution International License (CC BY). http://creativecommons.org/licenses/by/4.0/

(c) (;) 0 pen Access

\begin{abstract}
The scientific article presented here is intended to provide university teachers the theoretical basis for their work in the classroom, considering three principal theoretical learning paradigms: Behaviorism, cognitivism and constructivism; and four particular theories that have been labeled like constructivist (psychogenetic theory, meaningful learning theory, theory of strategic learning and the historical-cultural theory). Thus, this theoretical review provides guidelines to act in the university classroom that can lead to the elimination of "teaching without learning".
\end{abstract}

\section{Keywords}

Behaviorism, Cognitivism, Constructivism, Psychogenetic Theory, Meaningful Learning Theory, Theory of Strategic Learning, Historical-Cultural Theory

\section{Introduction}

Throughout time humans have demonstrated their curiosity to learn and get knowledge about how people learn. Since ancient times, some members of the civilized society have developed and proved ideas about the nature of learning process (Bigge \& Sharmis, 2001). In this way, psychologists from different theoretical approaches have tried to explain the psychological principles of learning, and they have used psychological methods to understand the educative process (Clifford, 1984).

Since last century there have been periods characterized by conviction that psychology will allow a scientific basis for education, supporting in the knowledge that scientific method has provided in order to address and solve educative problems (Coll, 2007). This is now called educational psychology.

According to Coll (1998), educational psychology has been set progressively as a result of an uninterrupted effort of application of principles, explanations and methods of the scientific psychology with the purpose to improve educative practices in general, and scholar education in particular (e.g., elaborate adequate and useful 
explanations to develop scholar planning).

Nevertheless, this development has been difficult conceptual and methodologically, since it comprehends two disciplines on its definition: psychology and education.

The object of study of educational psychology is closely related to education and the systematic nature of educational psychology comes from psychological research; it makes educational psychology to participate in both types of disciplines, without being totally defined by just one of them.

For Coll (1996) the educational psychologist’s professional activities appear basically in three working ways: teachers' formation, psychological research applied to education, and child clinic psychology.

In the same way, Ausubel, Novak and Hanesian (1978) state that the function of educational psychology in teachers' education is based on the premise that there are general implicit meaningful learning principles in the classroom which can be taken as derivation of one learning theory. The valid teaching theories and methods must be related to the nature of learning process in classroom and thus, with cognitive, affective and social factors that influence it.

These principles have been validated empirically and must be communicated with efficiency to current and futures professors. They give psychological foundation to thus they can discover by themselves the most efficient methods of teaching and to select with intelligence new and efficient options that otherwise would be obliged just to accept.

Consequently, educational psychologists are often defined as experts who apply principles of psychology to education, devoting their professional lives to understand learners, teaching process and instructional strategies that facilitate it (Henson \& Heller, 2000).

In the same way, Ausubel et al. (1978) state that the psychoeducational research tends to study the following types of learning problems:

- Discover the nature of the learning process aspects, which affect the acquisition and long-term retention of organized knowledge.

- The improvement of the capacity to learn and solve problems.

- Know cognitive and personality characteristics of the students, in order to understand how interpersonal, social, and environmental areas affect learning outcomes, as well as how the motivation affects learning and the ways in which the material can be assimilated.

- Determine the best and most efficient ways to present and organize learning material that would motivate and guide to concrete goals.

According to Ausubel et al. (1978) the general aspects of learning are those of interest to a psychologist; while learning in a classroom inside a social context, is a special area of educational psychologist. Therefore, the field of study of educational psychology can be directly inferred by the problems that teacher is facing in a classroom.

Thus, the reach of educational psychology as an applied science is very vast, and the potential rewards that are offered in a social value context to facilitate the learning of different subjects are really big (Ausubel et al., 1978).

Based on the propositions expressed by the previous authors, an important function of educational psychology can be extracted: teacher formation, in order to improve techniques by the application of new methods based on the psychological basis of learning.

Having said that the aforementioned psychological basis are part of learning theories, it can established defensible notions that can be effectively handled as decisive factors in a teaching-learning situation (Ausubel et al., 1978).

Consequently, this article is intended to provide a careful conceptual review of the different learning theories in order to deeply analyze the educational psychology's contributions to work done in the university classroom.

Since this conceptual review suggests actions that university teachers can realize following the corresponding theory, this theoretical review presented here is not only a "compendium of theories", if not that is aimed at students of psychology or educational sciences, teachers, teacher educators and researchers interested in the topic.

Although the title of this theoretical study intends to be used primarily at university education, is easily adaptable to teaching in other educational levels.

\section{Learning Theories}

There are general principles of learning derived from learning theories that can be empirically validated and 
communicated effectively to future teachers (Díaz Barriga \& Hernández Rojas, 2010).

A theory is a scientifically acceptable set of principles that explain a phenomenon. Theories provide frameworks for interpreting environmental observations and serve as bridges between research and education (Suppes, 1974).

The research findings are organized and systematically linked to the theories; without them, those data collections would be messy and professionals and researchers would lack an upper frame in which to hold themselves.

The learning psychological theories are many and vary, but they share the basic idea that learning processes play a central role in human development (Del Río, 1990). Before analyze the learning theories, the learning concept will be explain because is an indispensable component, prerequisite for any theoretical elaboration about teaching (Gimeno \& Pérez, 1995).

Learning involves acquisition and modification of knowledge, skills, strategies, beliefs, attitudes and behaviours. Learning is a daily occurrence that suggest a new skill or a new concept is learned in a random and unsystematically manner; however, if learning situation is carefully observed, it will be noted that learning is not as fortuitous as it seems (Castañeda, 2004).

It is virtually impossible to find a definition of learning that is accepted by all psychologists, but it can be said that those who study learning are interested in the process of change that occur as a result of experience (Mazur, 2013). Therefore the definition of learning most commonly found in the texts, states that learning is an enduring change in behavior or ability to act in a manner given, as a result of practice or other forms of experience (Castañeda, 2004; Shuell, 1986).

Mayer (2002) takes this concept and minimally modifies it and affirms that learning is a relatively stable change in the knowledge of someone as a result of the personal experience. According to the author, the difference between both definitions is that the change is not perdurable if not relatively stable and change is in knowledge, not behavior.

There is no one definition of learning accepted by all theorists, researchers and education professionals, due to the fact that there are as many and varied notions, because of existence of disagreements about exact nature of learning (Schunk, 2011).

However, a theory of learning tries to be a rational explanation, scientific, coherent and philosophically grounded of what learning concept involves, as well as the conditions where it manifests and the forms it takes (Castañeda, 2004).

There are different learning theories, each governed by knowledge and preconceptions that the different authors have had on the subject. In the same manner, learning researchers have sorted them according to their common and differential properties. For example, Bigge and Sharmis (2001) classify them into: mental discipline theories, theories of conditioning (stimulus-response, stimulus-response-consequence), and cognitive theories of gestalt field. Similarly, the classification of Pozo (2006) ranges from theories that favor associative learning and theories that lead to learning by restructuring.

Meanwhile Castañeda (2004) and Schunk (2011) divide the theories into behavioral theories and cognitive theories. Alvarez, Guerreiro and Sánchez (2005) only took into account the behavioral and constructivist principles in their study to determine what teaching strategies were used by teachers. Similarly Vera (2005) analyzed student's performance and classified the outcomes in two directions: behaviorist and constructivist.

In the same way, Mayer (2000) states that during the twentieth century, there have been three research paradigms regarding the processes of teaching and learning. The first of these paradigms (developed in the first half of the last century) is named behaviorism. That considers learning as a consolidation of responses, where the role of the student is to receive reinforcements and the role of the teacher is to give these reinforcements.

The second paradigm was nominated cognitivism, which declares that learning is the acquisition of knowledge (developed in the third quarter of the twentieth century). In the cognitivism the student acquires information passively and the teacher's job is to present information in a manner suitable to be processed.

The third and final paradigm developed in the last two decades of the twentieth century was labeled constructivism. This one conceived learning as the elaboration of knowledge, where teacher's function is to guide students cognitively, in order to get a directly participation in the construction of cognitive representations of reality.

As it can be observed, different classifications are mainly due to the conceptions of each author. For practical purposes and in accordance with the theoretical and empirical reviews, the classification of Mayer (2000) will be used to develop this section and the constructs behavioral learning theories, cognitive learning theories and 
constructivist learning theories will be used to the first, second and third paradigm.

The most important theoretical positions related to behavioral, cognitivist and constructivism principles will be discussed in this review. In some of these, the word "theory" is not used, since authors did not do it, but their theoretical position makes reference to it and according to their characteristics it can be say that this is a learning theory. In consequence here learning theories will be presented with the expected role or "obligations" of both, teachers and students.

\subsection{Behavioral Learning Theories}

Behaviorism was a considerable force in psychology in the first half of last century; thus many theoretical postures represent this behavioral position and explain learning process in terms of observable phenomena. In fact, it can be stated that the definition of learning that was presented here, is behaviorist in the theoretical roots.

Theorists of this trend argue that learning does not include thoughts and feelings, not because these internal states do not exist but because such an explanation is in the environment and in the history of every one (Batista \& Chadwick, 1993; Garza \& Leventhal, 2000).

Behaviorism was developed by Burrhus Frederick Skinner and assumes that the learning process takes place through conditioning (Nath \& Sajitha, 2010). According to Schunk (2011), behavioral theories believe that learning is a change in the rate, frequency of apparition or form of behavior (response), first of all as a function of environmental changes. Behavioral psychologists argue that learning involves the formation of associations between stimulus and responses.

According to Skinner (1953), it's more likely to give a response to a stimulus depending on the consequences, and the reinforcing consequences do more likely to occur again, while the aversive consequences do it less plausible. Therefore behavioral techniques have been used in education for a long time to promote desirable behaviors and discourage behaviors that are undesirable (Nath \& Sajitha, 2010).

\subsubsection{Teacher Duties}

University teachers have to accommodate the environment so that students respond appropriately to stimulus (Garza \& Leventhal, 2000).

The main role of the teacher in instructional process is to dispose reinforcement contingencies to enable or increase the probability of occurrence of the response to be learned. Skinner mentioned that what was really important for a teacher is not to seek or find another reinforcement different from the already existing ones in everyday situation, but that the teacher must have a better use of contingencies of those reinforcements, regarding the desired response (Batista \& Chadwick, 1993).

In order to students learn, in the behaviorism scheme, it is important that the design objectives are oriented to it. As Mager (2002) established, when an instructional objective is prepared it must considerer to take account these aspects:

- The teaching goal;

- The required level for the student to learn (or to do);

- What are the conditions (materials, processes and stimuli) in which the student must answer.

Throughout his work, Skinner (1953) based on behavioral principles, reported some general guidelines to improve teaching:

- Being clear about what is to be taught;

- Teaching first the least difficulty;

- Encouraging students to progress at their own pace;

- Programming topics;

- Structuring the content properly as learning does not depend on its degree of complexity or abstraction, but rather how it is presented in a chain (stimulus-response-consequence);

- Providing students with reinforcers when giving an answer;

- Setting realistic goals with the students, since large goals may discourage them and small goals may bore them.

The teacher, besides being aware of the importance of stimuli in learning, recognizes himself as a further stimulus, since in behaviorism it is known as observational learning, which is based on learning through imitation of behaviors initially presented by a person who becomes a role model (Garza \& Leventhal, 2000). In behaviorism the role model may be the same teacher or any of the peers the student that is expected to learn from. Wool- 
folk (2012), offers a number of tips to consider for this type of learning can become effective. Such as becoming yourself a role model for the behavior you want your students to learn. Try to do step by step and explicitly what students are expected to do, whether the learning of skills or attitudes is sought. Employ fellow students as role models, encouraging teamwork and make sure to take each of them to a student who usually gets what he expected, and make sure he is helped by his peers; ensure that students see that positive behaviors of others carry positive consequences, offering fair reinforcements, and seek the cooperation of students to serve as role models to the whole group.

\subsubsection{Student Duties}

The role of the student in behaviorism is passive; however there is the possibility that student learn to learn on his own through the programmed instruction strategy. What students have to do in a programmed instruction is to follow a series of steps that are called frames. Woolfolk (2012) mentions the fundamental principles established by O'Day, Kulhavy, Anderson and Maleczynski, to be taken into account in the design of matter of study, which are: specification of the objective to be achieved, pilot test of the course, allow the student to review the material at the pace that he wants to advance, immediate feedback and the division of material into small steps.

It is common to hear teachers about their disdain for the behavioral theories and their application in educational institutions of higher education, but adequate motivational systems including operationally behavior and corresponding consequence can "encourage" students to strive to get the school goals, ensure success by applying the elements previously mentioned by Skinner (1953).

\subsection{Cognitive Learning Theories}

Cognitive perspective emphasizes the acquisition of knowledge and mental structures and they are known as the Perspective of Processing Information or Theory of Information Processing in base of the simile they make between human brain and computer (Garza \& Leventhal, 2000).

The main perspective of these theories is the mental processing of information because these emphasize the fact that information is encoded in sensory memory, where perception and attention will determine what will be retained in memory for later use. In working memory, new information is linked to the knowledge of the longterm memory and could be activated to return to working memory (Woolfolk, 2012), this is known as information retrieval.

\subsubsection{Teacher Duties}

The application of this theory in the classroom implies that the teacher realizes the importance of environmental information perception through of the senses of the student. This involves different communication channels between teacher and student by presenting to them visual, auditory or kinesthetic instruction ways.

Once the information is presented to the student, it is essential that teacher be sure about the correct coding that students make of his words, otherwise the important process of attention would be affected.

If the student pays attention to the teacher at the time of presenting the information, such content will be placed in short-term memory up to 15 second. This is why, in the master classes where an expert in the subject exposes class to students and where he uses prepared verbalizations rarely has a direct effect on the learning process.

For information to be maintained in the long-term memory, such information should be worked, this way information retrieval will be successfully.

If someone wants to learn the information literally, it is advisable to use mnemonics techniques such as questionnaires, method of loci (memory palace), acrostics, using strong colors, songs, drawings, etc. (these techniques have been classified as traditional teaching techniques). Similarly, if the characteristics of the learning task indicate the need for conceptual elaborations, strategies of constructivism can be used: concept maps, comparative charts and tree diagrams (Sprinthall, Sprinthall, \& Sharon, 1996).

\subsubsection{Student Duties}

Students not only receive passively influence of environmental events, instead they actively choose, pay attention, ignore, think and make decisions while pursuing their goals (Woolfolk, 2012).

However, these processes depend mostly on environmental manipulation by their teacher and the exercises that are available to improve processes. 


\subsection{Constructivist Learning Theories}

Constructivism originally emerged as an epistemological trend, concerned to discern the problems of knowledge formation in humans. The constructivism theorists show that humans actively construct knowledge based on what they know and also with an active relation to others with whom they interact (Pimienta, 2007). Meanwhile, Carretero (2009) states that according to the constructivist position, knowledge is not a faithful copy of reality, but a construct of the human being and that such construction is done mainly with the patterns he already owns, or with the result of the interaction with the environment.

Coll (1990) mentions that constructivism is organized around three key ideas. The first one states that the students are ultimately responsible for their own learning process. The student is who constructs knowledge (or rather, reconstructs) and no one can replace him in that task. Second, the constructive mental activity of the student applies to the contents that already possess a considerable degree of processing. This means that the student does not have all the time to discover or invent, in a literal sense, the entire school knowledge. Since knowledge is taught in schools it is actually the result of the process of construction at social level, students and teachers can find already developed and defined large part of the program (Díaz Barriga \& Hernández Rojas, 2010). Thirdly, the role of teachers is set construction processes of students with culturally organized collective wisdom. This implies that the teacher's role is not limited to create optimal conditions for the student to display a constructive mental activity, but should guide and direct the activity explicitly and deliberately.

To conclude what is constructivism, Woolfolk (2012) mentions that all authors agree that constructivism represents a significant change in the interests of education by placing of the student's efforts to understand in the center of the educational enterprise.

In this regard, Morales (1998) states that in order for school learning to fulfill the function of being used in any context, it is necessary that the subject not only acquires a certain knowledge, but needs to have the opportunity to reconstruct it in diverse situations, making it necessary for the individual to learn to build knowledge by himself; in that sense, the teacher assumes the role of the facilitator of knowledge. This means that the teacher guides and encourages students in the learning process, so that they succeed in construction their own knowledge structures, which makes it easier to reconstruct this knowledge in different situations.

According to Cubero (2005), the importance and prominence of the term constructivism has led to the multiple use of the term. Díaz Barriga and Hernández Rojas (2010) agree with the opinion of Coll (1996), who argues that the constructivist stance on education is powered by the contributions of various psychological theories, among which are: the psychogenetic Piagetian approach, the theory of cognitive schemas, the ausubelian assimilation theory and meaningful learning, the Vygotskian sociocultural psychology, as well as some instructional theories, among others. And despite the authors of these theories are in different theoretical explanations, they agree with the principle of the importance of constructive activity of students in the realization of school learning.

Therefore, according to Hernández Rojas (2006) in the contemporary education theory, they acknowledge that to talk about just one type of constructivism in educational psychology is wishful thinking; it is necessary to recognize the existence of several types of constructivism theories that exercise their influence in the discipline and within themselves. For this reason there are various possibilities of constructivist approaches to try to understand and explain the enormous complexities of education, inside and outside of school. Similarly, the author claims that it is believed that a consensus on constructivism might be dangerous to some extent; since it could be confusing or it could generalize classifying everyone or almost everyone as constructivists.

Usually the constructivism theories put their trust in an active learner as constructor of himself, re-constructor and co-constructor of the knowledge of society and culture. It is considered that the student is a constructor of meanings, and an interpreter and creator of meaning in the classroom. In the same way, they also put their trust in a teacher that is committed to play an important role in the educative process by supporting, collaborating and enhancing a constructive activity; this means, that without the teacher suitable participation this could simply not be possible (Hernández Rojas, 2006).

Llovera (1998) suggests the following principles of constructivism:

- Learning is an internal and self constructed process;

- The degree of learning depends on the level of cognitive development;

- The starting point of all learning is prior knowledge;

- Learning is a process of reconstruction of cultural knowledge;

- Learning is facilitated from mediation and interaction with others; 
- Learning involves a process of internal reorganization of schemes;

- Learning occurs when what the student already knows and what he wants to know clash.

The following is a conceptual review of four theories that are considered more developed and more easily applied in the university classroom, according to Hernández Rojas (2008).

\subsubsection{Psychogenetic Theory}

In 90’s, texts about the construction of knowledge by individuals in different stages were present by Jean Piaget, which has been known as "psychogenetic theory" or "Piaget's theory of cognitive development".

This theory was born from observational studies made by Piaget to his children and in this contribution was really important to the study of psychology on cognitive development and intelligence.

The contributions of this theory to higher education lies in the significance of cultivating in the students the autonomy, rather than teaching them to blindly obey and assuming a status of conformity and not questioning what is presented as "knowledge" by teachers. This is based on the way in which individuals are able to construct their own knowledge.

\section{1) Teacher duties}

From Piaget's perspective, the main role of the teacher is to facilitate and guide students, so that they actively construct their own knowledge. Definitely, Piaget has always disagreed with the idea of transmitting knowledge already developed and deposited in the student as well as the use of the excessive verbiage as an educational resource (Piaget, 1999). According to the psychogenetic approach, the teacher should be treated as a facilitator and promoter of development and autonomy of learners. It certainly should be someone that has a solid background on problems, processes and characteristics of the school learning of the students on the defining features of the stages of the general cognitive development and the basic mechanisms of the various processes involved in the cognitive equilibration (assimilation, accommodation, reflective abstraction, cognitive conflicts, etc.) whose conceptualization is not the objective in this section.

Thus, the fundamental roles of the teacher according to (Hernández Rojas, 2006) are to:

- Promote an atmosphere of reciprocity, respect and self-confidence in the classroom.

- Give students opportunities to develop a self-initiated learning, mainly through indirect teaching (learning by discovery and exploratory), problem approach, relevant teaching activities and situations and to promote cognitive and socio-cognitive conflict in students.

- Try to create situations and cognitively valid experiences for the student.

- Reduce the level of authority, as much as possible, so that students do not feel subject to what teacher says when he tries to learn or know any school content and not to encourage blind dependence, neither moral and intellectual heteronomy.

- Introduction oneself not as the sole source of knowledge, but as a questioner and as an alternative source knowledge.

- Provide information, not to impose the truth and encourage students to consider important questions.

- Respect and enforce the errors and strategies of the student's own knowledge, and to not request simply the correct answer.

- Avoid the naive use of reward and punishment and, instead, encourage the students to construct their own moral values.

In the same way, Piaget (1999) emphasizes the need for teachers to guide or help students reach possible solutions if there are no valuable solutions.

\section{2) Student duties}

According to psychogenetic constructivism, teachers should give to students the opportunity to formulate their own explanations and hypotheses about the natural and social objects they are facing and trying to understand. Although at some point it may be considered that the explanations are wrong, it must avoid giving them away the correct answer and, instead, teachers must give them the answer in a different situation like in activities, problems, and small research group discussions; so that they can be realized and they can form their explanatory hypotheses and concepts. To prevent future situations, it is important not to provide the correct answer immediately nor solve their problems before moving forward; this is so they don't feel distrust towards the teacher.

It is considered that the activities that are done, should preferably be promoted by students so that they can be self-initiated (emerging from the interests and motivations of the student), which in most cases can result in a 
self teaching nature and is supposed to produce structuring consequences in their short or long term schemes. If activities are planned by the teacher and have to be realized by the students, it is highly desirable to allow the students to explore on their own before requiring a correct answer or to give them the formalized knowledge (Hernández Rojas, 2006).

In conclusion, the tasks structure should be according to their cognitive development level and they should be able to resolve them on their own. In this regard, at the higher education, it is expected that cognitive development is the same in all of the students, since most access to this level of education through an admission test. But, it is likely and desirable that at times the teachers need to make adjustments to the content or the ways the information to be transmitted to the students to ensure different levels of cognitive development and to promote understanding and autonomy, but without giving the answers to the problems presented.

\subsubsection{Meaningful Learning Theory or Assimilation Theory}

Undoubtedly, the education goal given by the assimilation theory is that students achieve meaningful learning from the program of any educational level. For Díaz Barriga and Hernández Rojas (2010) meaningful learning occurs when new information to learn is related to the existing information known by the student, not arbitrarily. To reach this, there must exist a learner disposition and logical meaning in the content or materials.

Novak says that the fundamental purpose of education is to enable learners to take charge of their own construction of meanings. Construction involves thinking, feeling and attitude; all aspects must be integrated to achieve a different and meaningful learning, especially to create new knowledge. In all educational situations, a share of actions as well as an exchange of meanings (and directions) between teacher and students occurs (Novak, 1998). The exchange is intellectually constructive and emotionally effective when it results in an improvement of the learner understanding of a part of the knowledge. In other words, when the two agents in the educational environment, teacher and learner, can successfully share or negotiate the meanings of a specific curricular content (a block or significant body of knowledge) then meaningful learning occurs (Novak, 2010).

Ausubel et al. (1978) found that students face to large, stable and hierarchically organized knowledge (in different disciplines, materials, modules, etc.) that have to be learned, since one of the central objectives of school education is to transmit the accumulated cultural heritage (socially valuated knowledge) to new generations. In this regard, it is necessary to ensure that these knowledge are significantly acquired in order to these bodies of knowledge are widely dominated.

Once the contents have been assimilated, it is possible to transfer them to other educational contexts. This is a determining factor of university education because college students study a program that has been created to meet the demands of society. Consequently what is learned in the classroom has no other purpose but to be applied in real life problem solving. Therefore problem solution becomes the appropriate indicator to assess whether or not there was significant learning.

\section{1) Teacher duties}

In the proposal of the assimilation theory, the teacher's role is to be an agent that seeks to foster meaningful learning of their students. He must be able to recognize when and at what time it may be valid to follow a strategy in the construction of meanings done by the student. The teacher should pay attention to the student and on the opportunities to build valuable meanings from the program content (Hernández Rojas, 2006).

Moreira (2005) mentions that it is not enough that students achieve meaningful learning, but it is necessary that the teacher encourage such learning as a critical activity, a critical learning in a perspective that can let the student is part of his culture and at the same time, be out of it. Within this type of learning the learner must have the ability to be critical of his cognitive proceses, and have the flexibility to analyze the different perspectives within a learning situation.

Díaz Barriga and Hernández Rojas (2010) have done a tremendous job forming teachers under the theory of meaningful learning that has been widespread in Latin America, since a variety of teaching and learning strategies for the development of meaningful learning in the classroom have been described. Similarly if the reader is interested in assessing whether such learning has worked in the classroom he can use the Teaching Strategies Scale for Meaningful Learnings de Méndez and González (2011).

Within the strategies conceptualized by Hernández Rojas and Díaz Barriga (2010) which are evaluated by the same instrument, you can find the positive-negative-interesting, conceptual maps, guided discussion, tree diagram, comparative table, summary, what I know-what I want to know-what I learned, previous question-answerafter question; among others. 


\section{2) Student duties}

From the standpoint of assimilation theory, the student displays an important role in the construction of significant learning. For this reason, it must conceptualize it, from this perspective, as a meaning building agent and at the same time, as a person who can share and negotiate with other learned meanings (Novak, 2010). As a result of substantive interaction between new information and previous knowledge, a significant learning, enrichment, modification and restructuration of previous ideas occurs, therefore building a new personal construction. When interacting new information with prior knowledge in substance or meaning, even in its simplest form, a new ideational construction within the cognitive structure occurs, recalling that the significance is continuous from the most superficial to the deepest (Hernández Rojas, 2006).

In this sense, the most important endogenous aspects involved in this process of meaning construction by the student are their cognitive structure (prior knowledge subsumption hierarchy in relationships) and their willingness to learn.

\subsubsection{Theory of Strategic Learning}

Currently most of the educational models in upper levels of educational institutions have the notion of learning to learn as a fundamental part of their philosophy (Méndez \& Torres, 2014).

The essential skills in learning to learn lead to the self-regulation use of learning strategies. Méndez and Torres (2014) indicate that the line between strategic learning with its notion of learning to learn and self-regulated learning is probably nonexistent, resulting rather complementary. In learning to learn it is essential that students become strategic, so that they can use different learning strategies to guide their own learning, which means to properly interpret the task, evaluate their weaknesses and strengths according to such task, and in this way they know what learning strategies are appropriate for such content. Similarly, directing their own behavior in relation to its study and continuous self-assessment by implementing the strategy and product modifications does self-regulation.

In addition to self-regulated learning in college students, learning to learn involves the need for students to have the ability to search for information fully developed; this means that the student can access appropriately the content he needs for his learning activities and to evaluate the relevance of these in relation to their needs for information and finally to solve the cognitive problem which made him search for such content.

- The proof of the above is mentioned by Monereo and Pozo (2001), who claims that there are at least five major challenges that the new information society poses to the future education;

- The predominance of the symbolic information in the productive sector. In this world, symbols and production systems that allow you to manipulate and manage material goods becomes increasingly important (example, information technology). The main raw material of human occupation consists of information that needs to be communicated, and be exchanged, assimilated and transformed in single and shared knowledge;

- The expiration of information. Every ten years, knowledge is largely renewed. Knowledge of the world has historicity, new knowledge is produced that outperforms the one before and is ready to be surpassed tomorrow by another one (Freire, 2004). Whether you like it or not, people are becoming lifelong learners, doomed to be updated constantly (though, of course, not all knowledge, strategies and attitudes are as perishable as other);

- The unmesurability and uncertainty of information. The problem is not having the information, but rather knowing how to select it and how to use it properly;

- The risk of substituting knowledge for the information. Simplifying messages, after ensuring the speed, economy and intelligible transmissions, can lead to the trivialization of the events and the shallowness of the interactions. It's not enough knowing how to access information; it requires a cognitive work that allows its transformation into real knowledge and the development of powerful cognitive resources to turn reflection, critical assimilation and creation into new information;

- The relativity of information. It is necessary for learners to know how to identify and select the most powerful points of view that fully explain a phenomenon or a specific problem, which are able to contrast differing perspectives and analyze their arguments and rationally justify their own points of view.

The school, in addition to teaching proper knowledge of each discipline (conceptual, procedural and attitudinal/ value-related type) socioculturally recognized or valued, should promote the development of cognitive and selfregulatory strategies, reflective/metacognitive knowledge and adaptive motivational patterns that imbue students with the tools to become more effective and reflective learners. This, in return, allow them access to smart, se- 
lective and critical knowledge in such a form that they may even go beyond school contexts as lifelong learners in this new society of information. The educational institution should promote an academic culture in which the student becomes a strategic learner, self-regulating, reflective, critical, and simultaneously learner and the wanting to continue learning on their own (Hernández Rojas, 2006).

Among the most significant competitive strategies to promote school and should be somehow present as strategic/transverse axes within the program of the various cycles, would be the following (Monereo \& Pozo, 2001): 1) know how to look for information in the selectively reviewed form; 2) analyze problems to review in a justified manner; 3) listen to dialogue; 4) talk to convince; 5) read to understand; 6) write to argue; 7) cooperate to find work; 8) know how empathize to shared; and 9) to learn to set reasonable goals.

\section{1) Teacher duties}

To form strategic students it is necessary to have strategic teachers who dominate teaching strategies and learning strategies perfectly, to enable students to use them.

In another way, in the educational model where the student is strategic and the teacher is a facilitator, the importance lies in the design. This means that the teacher designs a course in which he needs to use his theoretical and practical knowledge about learning and its various forms of assessment and application in different contexts. Consequently, the formation of the teacher in education is vital in this theory.

The strategies teacher should have a whole set of skills and strategies that will provide appropriate tools to create, interpret and analyze situations in which they will try to promote strategic learning. Teachers also seek to promote the acquisition of cognitive strategies in their students, particularizing in the areas of teaching or program materials. In this sense, the teacher should encourage the student's awareness and reflection on the decisions that he takes, so that it is promoted the development of metacognitive, reflective and self-regulatory processes that allow students to become autonomous learners and self-regulated (Hernández Rojas, 2006).

In relation to the self-regulation that is expected as a result of using strategies, Pérez Cabaní (1997) indicates that another central premise from this perspective is to consider that it is possible to teach students to develop these strategic behaviors, and support them to learn to make decisions about what and how to learn.

\section{2) Student duties}

The student in this theory is understood as an active, reflective and self-regulating agent (Ertmer \& Newby, 1996) that needs to know how to access, how to select and what to do with the information to be learned. In this sense he must be trained with a wide repertoire of strategies for how to make intelligent use of them. He should also learn to develop greater awareness of himself as an apprentice in relation to certain tasks, content and knowledge areas that he faces everyday inside and outside the classroom (Hernández Rojas, 2006).

\subsubsection{Historical-Cultural Theory}

The main author in this theory is Lev Vygotsky, who emphasizes in a social construction of knowledge which is co-constructed by the person and others. Hernández Rojas (2006) states that cultural development lines are plastic and multidirectional, and can be redirected as a derivation of cultural and educational practices in which learners participate and develop; similarly, the teacher in the background is guiding the reconstruction processes and co-construction, he not necessarily uniquely determines learning paths through which learners can move: learners can also contribute significantly.

Research derived from this theory in educative environment at university level use pedagogic discourse as the object of their studies. This is used in the educational situation and it is the central element through which knowledge is constructed and creates new ways of intermental thinking, in addition to enabling access to forms of cultural and disciplinary communities (Hernández Rojas, 2006), which show how the students learn the meanings constructed and reconstructed of their own knowledge through interaction with others.

It is through this sociocultural practice that accumulated and culturally organized knowledge by generations is transmitted and the processes of social development with personal development are interwoven, which generate each other. For Vygotsky (Hernández Rojas, 2006), the development processes are not independent of the cultural educational processes, but both are linked from the first day of the child's life, while he is participating in a sociocultural context and there are others (parents, peers, school, etc.) who interact with him to teach him culture and cultural artifacts or instruments.

From this approach, it is then appropriate to consider the educational goals in terms of what determines the particular culture as a valuable and relevant knowledge to be learned by their younger members. It should be clear that these educational processes are not possible without the support of other more capable, whose help 
and participation is essential since, in its absence, the use of the tools and knowledge that offers the sociocultural environment would become very difficult. Also, such appropriation by students is not a passive, but essentially creative, innovative and original activity, that allows that, sooner or later, knowledge artifacts are enriched by the new generational influence, significantly altering the process of socio-historical accumulation that had been achieved (Hernández Rojas, 2006).

1) Teacher duties

Following the Vygotskian idea, it could be said that the teacher is an agent that guides and provides a mediating role to students to carry out their approach to knowledge artifacts, and cultural practices. The teacher should share the meanings he knows about educational knowledge agents, about artifacts and knowledges; and should also guide the students to get an interpretation, knowledge and socially expected or valued practice of these artifacts (Hernández Rojas, 2006).

Trading or sharing between teachers and students should be seen as a joint of construction, which progressively unfolds through a series of language teaching aids and devices strategically organized, in order for students to complete appropriating artifacts and cultural knowledge, that develop and achieve internal performance (reconstruction) of the cultural artifacts. Synthetically, the teacher must know how to engage the cultural knowledge expressed in the program with internalization processes underlying the acquisition of such knowledge by the student (Coll, 2001).

Also, in his teaching, the teacher should try creating and constructing zones of proximal development with students via the structuring of flexible and strategic scaffolding. But do not forget that while areas can mainly aim at promoting cognitive change in a certain direction (the curricular intentions), they can also be considered as areas of joint construction, given that student participation can influence, and in fact influences the structuring of activities, to the extent that they can get to take on different characteristics than expected. Whether in one case or another, at the end, certain activities shall be guided, directed and supervised by the teacher to some desired or at least accepted direction (Hernández Rojas, 2006).

\section{2) Student duties}

The student is a social being, main character and product of many social interactions and cultural practices that are involved throughout his school and extracurricular life. Higher psychological functions, in fact result from these social interactions, which also maintain organizational properties in common. Thanks to the educational process supported by social interaction processes, the student gets inculturation and socializes while being individualized and self-realized. It is in that sense that a person appropriates the cultural knowledge in the broadest sense (knowledge, skills, artifacts, cultural and linguistic practices). Such cultural knowledge, initially, will be immersed in the interindividual dimension and subsequently through the application of mechanisms of internalization, will become part of the intraindividual level, and then again becomes externalized trough an interindividual plane when required in certain cultural practices (Hernández Rojas, 2006).

\section{Conclusion}

As narrated, the contributions of educational psychology in higher education are mainly located in the application in the classroom of the mentioned positions.

The key point of the process of teaching and learning in each theory lies in different aspects. Since the behavioral theory seeks to introduce students to the organized content step by step to produce a "correct answer", cognitivism theory seeks that the perception of the content is appropriate to encourage retention and recovery; other posture has an interest in the fact of making sure that students are becoming autonomous learners to formulate their own hypotheses and explanations of phenomena (psychogenetic theory); meaningful learning theory relates what was seen in the classroom to previous content to thereby be able to transfer to other contexts; theory of strategic learning have an interest in students to make use of various strategies; and last, historicalcultural theory stand out in your acquired knowledge received in the environment.

It is necessary to differentiate the behavioral theory (known as traditional teaching) of the other approaches, as this position is reflected in master class the teacher is the sole repository of knowledge, which educates students through a properly organized didactic language (Méndez \& González, 2013); unlike other theoretical positions where students have an active role on the teaching-learning process.

When a course is designed for university level is essential to take into account the different positions that are presented by Coll (1996), who mentions that choosing a single learning theory as a reference point to analyze, explain and understand the school processes of teaching and learning does not mean giving up on using alterna- 
tive theories that may also help to understand certain aspects of these insufficiently studied and explained by the theory that was chosen.

And as mentioned, the role or student engagement with learning is merely an extension of the obligations of the teacher, as he is responsible for this process to be done successfully. Dedicating enough time in the formation as a teacher is the only way to guarantee the learning of the student.

The central argument is that while the social constructivist perspective has significantly illuminated our understanding of assessment, inadvertently the very object of assessment—knowledge—has been eclipsed (Shay, 2008). It revealed a broader, more holistic conception of student-centred learning which is largely ignored in the literature and included ideas such as personal growth, consciousness raising and empowerment. It raises the question of whether humanist interpretations of student-centred learning should be more explicitly considered across the disciplines (Tangney, 2014).

Finally, it is clarified that the application of learning theories in the classroom, is performed by means of teaching strategies and learning strategies, because these procedures or set of actions that the teacher in the classroom lead, do not arise from an isolated or without the support of theoretical foundation; on the contrary, the root of the strategies, both, teaching and learning, is grounded in psychological theories that have tried to explain what happens in the learner (Batista \& Chadwick, 1993).

\section{Acknowledgements}

Financial support to this academic effort was provided from a Mexican government research grant named PROMEP.

\section{References}

Alvarez, L., Guerreiro, Y., \& Sánchez, A. (2005). El uso de estrategias constructivistas por docentes de inglés con fines específicos [The Use of Constructivist Strategies by Teacher of English for Specific Purposes]. Revista Venezolana de Ciencias de Sociales, 21,101-114.

Ausubel, D., Novak, J., \& Hanesian, H. (1978). Educational Psychology: A Cognitive View (2nd ed.). New York: Holt, Rinehart and Winston.

Batista, J., \& Chadwick, C. (1993). Tecnología educacional: Teorías de instrucción [Educational Technology: Theories of Instruction] (2nd ed.). Barcelona, España: Paidós.

Bigge, M., \& Sharmis, S. (2001). Learning Theories for Teachers (5th ed.). New York: Pearson.

Carretero, M. (2009). Constructivismo y Educación [Constructivism and Education] (2nd ed.). Buenos Aires, Argentina: Paidós.

Castañeda, M. (2004). Los medios de comunicación y la tecnología educativa [The Media and Educational Technology]. México D.F.: Trillas.

Clifford, M. (1984). Educational Psychology. In Encyclopedia of Education. New York: Macmillan.

Coll, C. (1990). Un marco de referencia psicológico para la educación escolar. La concepción constructivista del aprendizaje y la enseñanza. In C. Coll, J. Palacios, \& A. Marchesi (Eds.), Desarrollo psicológico y educación II. Psicología de la Educación [Psychological Development and Education II. Educational Psychology] (pp. 435-454). Madrid, España: Alianza Editorial.

Coll, C. (1996). Constructivismo y educación escolar: Ni hablamos siempre de lo mismo ni lo hacemos siempre desde la misma perspectiva epistemológica. [Constructivism and school education: We not always talk about the same, we not always do it from the same epistemological perspective]. Anuario de Psicología, 69, 153-178.

Coll, C. (1998). Psicología de la educación, una disciplina aplicada [Educational Psychology, an Applied Discipline]. Cataluña, España: Universitat Oberta de Catalunya.

Coll, C. (2001). Constructivismo y educación: La concepción constructivista de la enseñanza y el aprendizaje. In C. Coll, J. Palacios, \& A. Marchesi (Eds.), Desarrollo psicológico y educación II. Psicología de la Educación [Psychological Development and Education II. Educational Psychology] (pp. 157-188). Madrid: Alianza Editorial.

Coll, C. (2007). Constructivismo e intervención educativa. Como enseñar lo que hay que construirse. In E. Barbera, A. Bolivar, J. Calvo, C. Coll, J. Fuster, M. Garcia et al. (Eds.), El constructivismo en la práctica [Constructivism in Practice] (pp. 5-36). Madrid: Grao.

Cubero, R. (2005). Perspectivas constructivistas: La intersección entre el significado, la interacción y el discurso [Constructivist Perspectives: The Intersection of Meaning, Interaction and Discourse]. Madrid: Grao. 
Del Río, M. (1990). Comportamiento y aprendizaje: Teorías y Aplicaciones escolares. In C. Coll, J. Palacios, \& A. Marchesi (Eds.), Desarrollo psicológico y educación II. Psicología de la Educación [Psychological Development and Education II. Educational Psychology] (pp. 33-53). Madrid: Alianza Editorial.

Díaz Barriga, F., \& Hernández Rojas, G. (2010). Estrategias docentes para un aprendizaje significativo. Una interpretación constructivista [Teaching Strategies for Meaningful Learning. A Constructivist Interpretation] (3rd ed.). Mexico, D. F.: McGraw Hill.

Freire, P. (2004). Pedagogia da autonomía. Sao Paulo: Faz e Terra.

Garza, R., \& Leventhal, S. (2000). Aprender cómo aprender [Learning How to Learn] (3rd ed.). México, D. F.: Trillas.

Gimeno, J., \& Pérez, A. (1995). Comprender y transformar la enseñanza [Understand and Transform Teaching]. Madrid: Morata.

Henson, K., \& Heller, B. (2000). Psicología educativa para la enseñanza eficaz [Educational Psychology for Effective Teaching]. México, D.F.: Internacional Thompson Editores.

Hernández Rojas, G. (2006). Miradas constructivistas en psicología de la educación [Constructivist Perspectives on Educational Psychology]. México, D.F.: Paidós.

Hernández Rojas, G. (2008). Los constructivismos y sus implicaciones para la educación [Constructivist and Their Implications for Education]. Perfiles Educativos, 30, 38-77.

Llovera, A. (1998). Desarrollo de procesos cognoscitivos [Development of Cognitive Processes]. Caracas: Universidad Pedagógica Experimental Libertador.

Mager, R. (2002). Cómo formular objetivos didácticos: El primer paso para el éxito de la formación [Preparing Instructional Objectives: A Critical Tool in the Development of Effective Instruction]. Barcelona: Gestión 2000.

Mayer, R. (2000). Diseño educativo para un aprendizaje constructivista. In C. Reigeluth (Ed.), Diseño de la instrucción: Teorías y modelos Part I [Instructional Design: Theories and Models Part I] (pp. 153-172). Madrid: Santillana.

Mayer, R. (2002). Promise of Educational Psychology: Teaching for Meaningful Learning. Washington: Merril.

Mazur, J. (2013). Learning and Behavior (7th ed.). Upper Saddle River, NJ: Prentice Hall.

Méndez, L., \& González, M. (2011). Escala de estrategias docentes para aprendizajes significativos: Diseño y evaluación de sus propiedades psicométricas [Teaching Strategies Scale for Meaningful Learnings: Design and Evaluation of Its Psychometric Properties]. Revista Electrónica Actualidades Investigativas en Educación, 11, 1-39.

Méndez, L., \& González, M. (2013). Evaluación de la Escala de estrategias docentes para aprendizajes significativos (EEDAS) [Evaluation of Teaching Strategies Scale for Meaningful Learnings]. Revista Ciencia UANL, 16, 58-77.

Méndez, L., \& Torres, G. (2014). Estrategias de aprendizaje y motivación en universitarios de dos modelos educativos distintos [Learning Strategies and Motivation among University Students in Two Different Educational Models]. Ciencia UANL, 17, 52-62.

Monereo, C., \& Pozo, J. (2001). ¿En qué siglo vive la escuela? El reto de la nueva cultura educative [In What Century Does School Live? The Challenge of the New Educational Culture]. Cuadernos de Pedagogía, 50-55. http://www.researchgate.net/publication/39138924_En_qu_siglo_vive_la_escuela

Morales, E. (1998). Efecto de una didáctica centrada en la resolución de problemas empleando la técnica heurística V de Gowin y mapas conceptuales en el razonamiento matemático [Effect of a Didactic Centered in Problem Solving Using Gowin's V and Concept Maps in Mathematical Reasoning]. Revista Latinoamericana de Investigación en Matemática Educativa, 2, 77-91.

Moreira, M. (2005). Aprendizaje Significativo Crítico [Critical Meaningful Learning]. Indivisa: Boletín de estudios e investigación, 6, 83-102.

Nath, B. \& Sajitha, P. (2010). Psychological Approaches to Learner Centered Curriculum in Kerala. http://www.eric.ed.gov/PDFS/ED513964.pdf

Novak, J. (1998). The Pursuit of a Dream: Education Can Be Improved. In J. Wandersee, \& J. Novak (Eds.), Teaching Science for Understanding: A Human Constructivism View (pp. 3-28). New York: Academic Press.

Novak, J. (2010). Learning, Creating, and Using Knowledge: Concept Maps as Facilitative Tools in Schools and Corporations. Journal of E-Learning and Knowledge Society, 6, 21-30.

Pérez Cabaní, M. L. (1997). La formación del profesorado para enseñar estrategias de aprendizaje en situaciones instruccionales interactivas. In M. P. Cabaní (Ed.), La enseñanza y el aprendizaje de estrategias desde el curriculum [Teaching and Learning Strategies from the Curriculum] (pp. 49-71). Girona: Horsori.

Piaget, J. (1999). De la Pedagogía. Buenos Aires: Paidós.

Pimienta, J. (2007). Metodología Constructivista: Guía para la planeación escolar (2nd ed.). México, D.F.: Pearson/Prentice Hall. 
Schunk, D. (2011). Learning Theories: An Educational Perspective (6th ed.). New York: Pearson Educación.

Shay, S. (2008). Beyond Social Constructivist Perspectives on Assessment: The Centring of Knowledge. Teaching in Higher Education, 13, 595-605. http://dx.doi.org/10.1080/13562510802334970

Shuell, T. (1986). Cognitive Conceptions of Learning. Review of Educational Research, 4, 411-436.

Skinner, B. (1953). Science and Human Behavior. New York, USA: Macmillan.

Sprinthall, N., Sprinthall, R., \& Sharon, O. (1996). Psicología de la educación [Educational Psychology] (6th ed.). México, D.F.: McGraw Hill.

Suppes, P. (1974). The Place of Theory in Educational Research. Educational Researcher, 3, 3-10. http://dx.doi.org/10.3102/0013189X003006003

Tangney, S. (2014). Student-Centred Learning: A Humanist Perspective. Teaching in Higher Education, 19, $266-275$. http://dx.doi.org/10.1080/13562517.2013.860099

Vera, L. (2005). Estrategias docentes con enfoque constructivista en el rendimiento académico de la Geografía de Venezuela en Educación Superior [The Effect of Educational Strategies within a Constructivist Focus on Academic Performance in Higher Education Courses in Venezuelan Geography]. Revista Venezolana de Ciencias Sociales, 9, 505-519.

Woolfolk, A. (2012). Educational Psychology (12th ed.). New York: Pearson Education. 
Scientific Research Publishing (SCIRP) is one of the largest Open Access journal publishers. It is currently publishing more than 200 open access, online, peer-reviewed journals covering a wide range of academic disciplines. SCIRP serves the worldwide academic communities and contributes to the progress and application of science with its publication.

Other selected journals from SCIRP are listed as below. Submit your manuscript to us via either submit@scirp.org or Online Submission Portal.
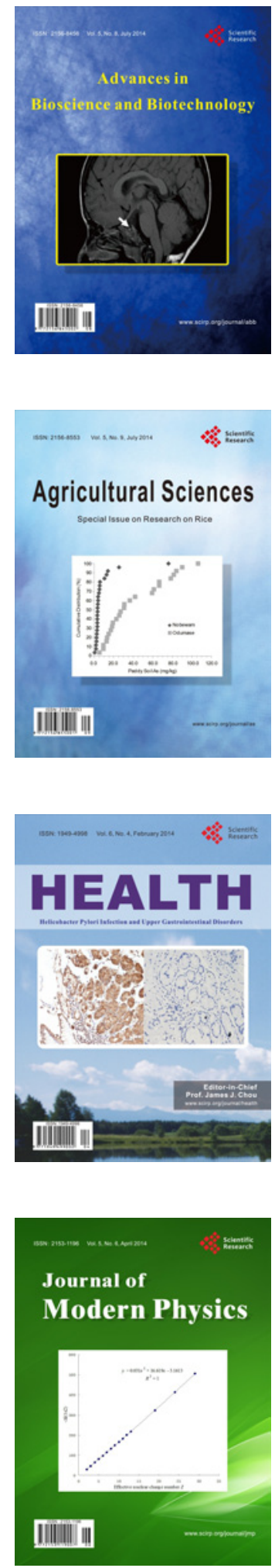
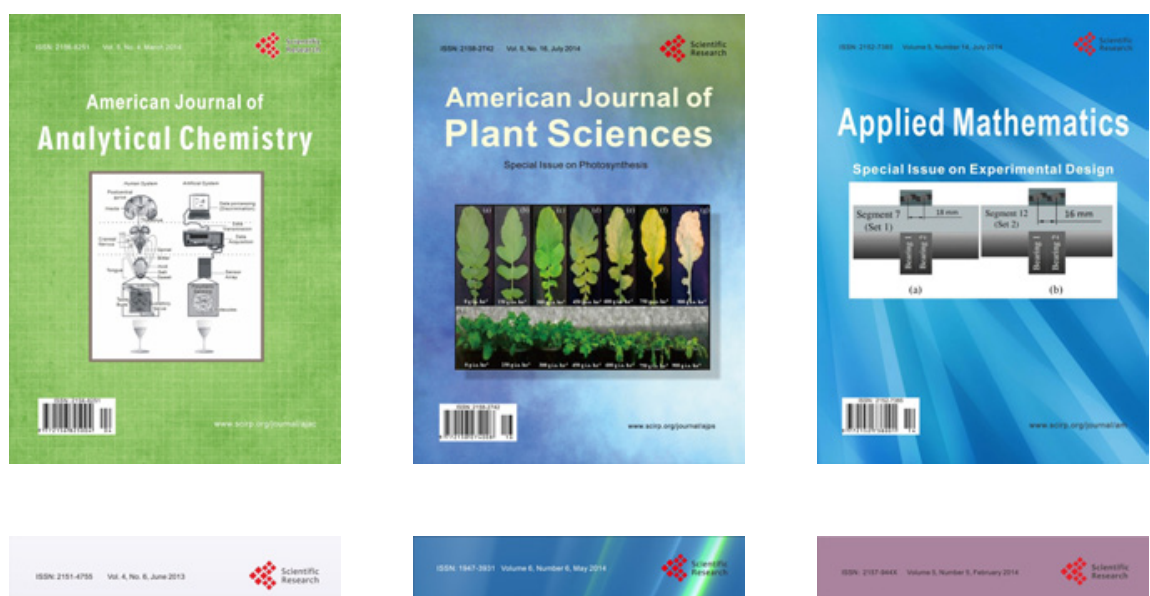

Creative Education
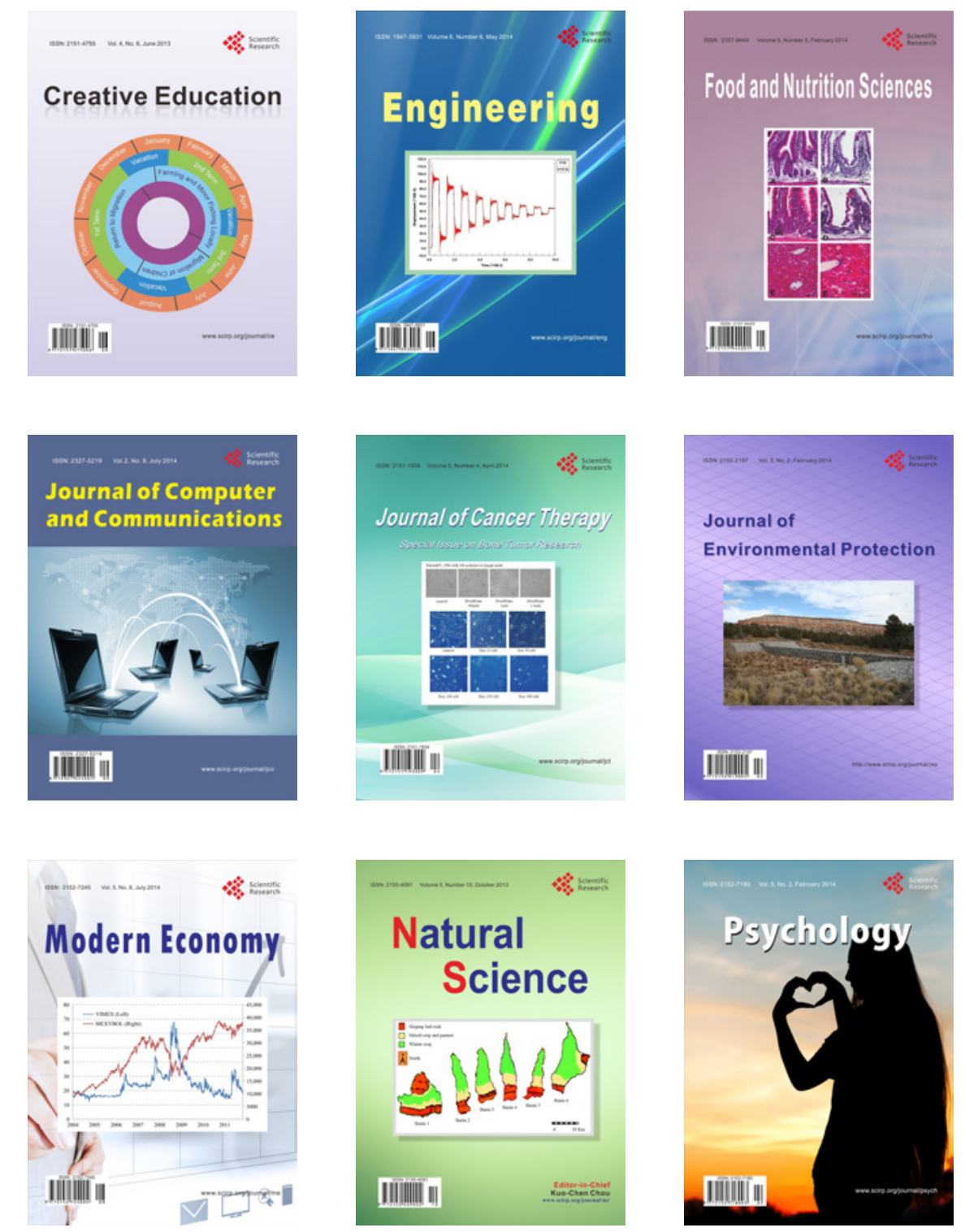